\title{
11
}

\section{The Development of ITEM in England and Wales}

\author{
I.D. Selwood \\ The University of Birmingham, School of Education, Edgbaston, Birmingham \\ B15 2TT, United Kingdom.
}

\begin{abstract}
In the United Kingdom the early 1970's saw the introduction of teaching about computers, the early 1980's the use of computers to enhance teaching and learning, and the early 1990's have witnessed the wide scale introduction of Information Technology in Educational Management (ITEM). The first part of this paper examines briefly the impetus behind the broad adoption of ITEM in England and Wales. The major part of the paper reports on a survey of Local Education Authorities (LEAs) in England and Wales. Statistics are presented which demonstrate the comprehensive take up of ITEM over a short period of time. How projects were co-ordinated; what applications were being run, and what proprietary systems were chosen; the hardware used; the level of training and support provided for schools implementing and running ITEM systems, are all discussed.
\end{abstract}

Keyword Codes: C.5.3, H.4, K.3.1

Keywords: Microcomputers; Information Systems Applications; Computer Uses in Education.

\section{BACKGROUND}

Even before microcomputers were first introduced into schools in the United Kingdom the computerisation of many aspects of school administration had been proceeding in a piecemeal manner for over twenty years [1]. However, in 1988 the Government of the United Kingdom passed the Educational Reform Act (ERA) [2], this one piece of legislation has resulted in massive changes to the way in which education is organised and managed within England and Wales. One of the major features of the ERA was the compulsion on LEAs to delegate much of their managerial and financial powers to schools, this lead to what has become known as LMS (Local Management of Schools).

Whilst there was no compulsion within the ERA for schools to introduce ITEM the implications of the Act are such that its introduction seemed inevitable. The Coopers and Lybrand report on LMS [3] had suggested that schools would need computer-based management information systems, this was followed by the Department of Education and Science's (DES) Circular 7/88 [4] which again identified this need. In the same month the government announced its intention to offer Education Support Grants (ESG) [5] totalling $£ 25$ million over the three year period commencing April 1989 for: introducing appropriate 
information systems into all schools with delegated budgets; setting up LEA support teams to assist with this activity; training of relevant school staff. ESG grants were subsequently increased and extended in this area. The stage was set for the co-ordinated and massive introduction of ITEM into schools within England and Wales.

\section{METHODOLOGY}

The content of this paper is derived from a number of sources. The two major instruments were questionnaires addressed to Local Education Authorities in England and Wales. The first survey was undertaken by the Local Authority Management Services and Computer Committee (LAMSAC) in 1989, and the results published [6]. In 1991/92 I decided to carry out a follow-up survey to obtain an overview of how much progress had been made in the intervening period. LAMSAC no longer existed, so I obtained permission from the Local Government Training Board, who had taken over some of LAMSAC's roles, to replicate the earlier study, thus allowing direct comparisons of data collected. Minor amendments were made to the content of the questionnaire to simplify the respondents task, and also to obtain some extra data concerning training and support. Further data and information has been drawn from a variety of sources including Department for Education (DFE) (formerly the DES) publications.

\subsection{Objectives}

The main focus of both surveys was on the proprietary systems used by schools for administration purposes. The two questionnaires were designed to ascertain a wide range of information including:-

- Numbers and types of schools with live computer administration systems;

- Which proprietary packages were being used, and which had been trialled and rejected together with some subjective views of the packages;

- What applications were being run;

- How the LEAs had chosen the software;

- How progress was being monitored and controlled;

- What hardware was being used to run the systems;

- Training and support offered to schools running systems;

\subsection{Respondents}

Ideally, systems managers and/or headteachers in all schools in England and Wales would have been targeted, but LAMSAC had, in planning their original survey, decided to address the questions to LEAs for reasons of economics and relating to problems of chasing and evaluating responses,

"Specifically it was accepted that:

- The evaluation by LEAs of the grass-roots value of schools systems would be based on second-hand information in many cases;

- LEAs may not necessarily know of systems being developed independently or inhouse by schools in their area;

- The opinions of LEAs of the value of authority-wide standard selections of software may not be consistent from area to area; 
- Non-returned questionnaires are difficult to trace in a large local authority department.

However, all these reservations apart, LEAs are in by far the best position to give objective and balanced views of the activities of their schools." [6, page 6]

As LAMSAC had adopted the approach of targeting LEAs I felt obliged to adopt the same approach and echo their reservations relating to it.

\subsection{Questionnaire Design}

The LAMSAC questionnaire was divided into four parts: one mandatory and three optional parts relating to the stage of implementation of ITEM that each authority had reached (Computers installed and running live systems, actively planning to introduce computers, no plans). However, as I felt that considerable progress should have been made in the intervening period, the follow-up questionnaire consisted only of two sections. The first section of the questionnaire was designed to obtain a general picture of the LEA whilst the second section, based on LAMSAC's section B, concerned the implementation of ITEM in the LEAs' schools.

\section{RESULTS}

In the following I will discuss predominantly the findings of the follow-up survey, however these findings will be compared to those of LAMSAC, and others where data is available.

\subsection{Response rate}

The LAMSAC survey achieved a $61 \%$ response rate from the 104 addressees, whilst my questionnaire attained a 53\% response from 119 addressees, the variation in number of addresses being accounted for by the intervening break up of the Inner London Education Authority (ILEA). Though both response rates are not high the two surveys achieved a good representative spread of the various types of LEAs in England and Wales, and the base of both surveys is approximately a $50 \%$ sample of all schools. The LAMSAC survey covered 16,775 schools, of which $13 \%$ were secondary whilst the follow-up covered 13,839 schools of which $14 \%$ were secondary.

\subsection{Co-ordination of projects}

Predictably, most LEAs, had set up some sort of working or steering group to advise, control and monitor the introduction of ITEM. The structure of these groups varied, as did their titles, powers and prime area of concern. The groups normally included education officers, LEA information technology officers and co-opted school heads, some LEAs had included union representation, and representatives of school based secretarial staff, though the number reporting both of these were low. The prime concern of a significant number of these groups was the introduction of Local Management of Schools (LMS) and they had the also been given the responsibility of co-ordinating developments in ITEM. Project teams had been set up by a third the responding LEAs and these had taken on the role of implementing and monitoring the project either jointly with the working group but more often than not replacing it. Most LEAs had set up a support team, a subject which will be dealt with in more detail later, and these teams had in many instances taken on the role of implementing and monitoring the project either jointly with the working group or by replacing it. User groups were reported as being set up and used in the co-ordination, implementation and monitoring process in fourteen LEAs. 


\subsection{Special Problems}

One opened question was concerned with special problems associated with introducing computers for school administration across the LEA. The variety of problems mentioned was nearly as great as the number of respondents. However, significant numbers of LEAs highlighted the training of school based staff, noting such issues as costs and quality of training, availability of staff for training, including time to practice the skills taught on courses, and time scales for training (and implementation).

A second significant group of problems involved the logistics of visiting schools to install, support and upgrade systems. The major concern here related to the size and cost of the team required to adequately support the initiative, the problem being exacerbated in the larger rural authorities which tended to have large numbers of small schools spread over a large geographical area. The financial problem for these geographically larger authorities was added to in some cases by having to set up and staff two training centres in different parts of the authority. Small schools also create an interesting problem in that they physically may not have the space to install systems. Five authorities claimed not to have had any problems, due to the consultation procedures they had undertaken

The problems previously noted by the LAMSAC survey of schools being resistant to standardisation and the need for cheaper and easier communications were only noted by four and one authorities respectively in the follow-up.

\subsection{Requirements for Outside Help and Information}

In response to my question "Are there any areas in which you would like some outside help or advice? What sort of assistance would be most appropriate?" Twenty-five LEAs responded "No", and seven felt they needed help with funding. A wide range of requirements for outside help had been noted by LAMSAC. However, possibly due to the publication of 'Computerbased administration systems in schools' [6] which may have met many of the LEAs requirements regarding information, or presumably having gained three years experience, LEAs seemed to feel that they had either solved their problems or had found the outside help they required. A general interest was shown by many respondents in finding out about the experiences of other LEAs, especially relating to training, support, and networking.

\subsection{Installed Systems}

In response to the questions concerning live computer administration systems. The following information was obtained.

Table 1

Installed systems.

\begin{tabular}{lcccc}
\hline & Sept. 1988 & $\begin{array}{c}\text { July 1989 } \\
\text { (Predicted) }\end{array}$ & Feb. 1992 & $\begin{array}{c}\text { July 1992 } \\
\text { (Predicted) }\end{array}$ \\
\hline Primary & $3 \%$ & $7 \%$ & $41 \%$ & $67 \%$ \\
Middle & $11 \%$ & $23 \%$ & $69 \%$ & $88 \%$ \\
Secondary & $46 \%$ & $70 \%$ & $98 \%$ & $99 \%$ \\
\hline
\end{tabular}

Over the period covered by the two surveys it can be clearly seen that significant progress in terms of live systems installed was made. Primary schools appear to be trailing considerably. The major reason for this is, initially primary schools with less than 200 pupils were excluded from LMS schemes [2] and therefore were not included in schemes to introduce computerised 
administration systems into schools. However, in noting this trend in 1989 LAMSAC [6] claimed

" the rate of implementation of new administrative systems in primary schools is likely in future to be very much higher: systems are simpler and much of the pattern of administrative computing will already have been set by secondary school installations; and the major problems will have been identified." [page 10]

A somewhat over simplistic view. There are over six times as many primary schools as there are secondary schools represented in these two surveys; systems until very recently have not been developed with primary schools in mind; and primary schools need not have the same range of problems as secondary. Responses discussed later bear out some of these suggestions.

\subsection{Installed Applications}

The LAMSAC questionnaire next examined in some detail the applications that had been implemented by each school. In designing my questionnaire and having the benefit of seeing the results obtained by LAMSAC I made the decision not to gather specific information on each of the main areas of application, but to allow respondents to give detailed information if they felt so inclined, few did. The reasons for this approach were: that the schools were not answering the questions; and any answers gathered would rely on the respondents interpretation of the activity in the LEAs schools. This concern over the accuracy of the perceptions of LEA respondents in this area is possibly justified when one compares the following table with DFE statistics, included in brackets, collected directly from a sample of schools in March 1989. [7]

Table 2

Summary of Installed Applications

\begin{tabular}{lccc}
\hline & $\begin{array}{c}\text { Primary } \\
\%\end{array}$ & $\begin{array}{c}\text { Middle } \\
\%\end{array}$ & $\begin{array}{c}\text { Secondary } \\
\%\end{array}$ \\
\hline Accounting & $68(61)$ & 82 & $93(95)$ \\
Timetabling & $4(4)$ & 18 & $43(64)$ \\
Pupil Records & $88(44)$ & 98 & $99(84)$ \\
Staff Records & $70(26)$ & 69 & $87(69)$ \\
Word Processing. & $92(82)$ & 98 & $95(100)$ \\
\hline
\end{tabular}

$\%$ responding based on number of schools reporting live systems

The results shown above are in no way surprising, one would expect word processing to be the most widely used application, pupil record systems tend to be at the centre of all the modular integrated packages available within the UK, and with the emphasis on LMS accounting is bound to be a high priority. The differences in the two sets of figures can be accounted for: The variation in the numbers of secondary schools reporting timetabling is used is probably due to the fact that there are a number of packages that can be purchased, for a variety of timetabling tasks, that schools have probably bought for themselves. The DFE question concerning pupil records also included assessment. Staff records in primary schools may well be seen as a low priority compared with finance and pupil records, and primary schools are at an earlier stage of development. 


\subsection{Uptake of Proprietary Software Systems}

There were two clear market leaders. SIMS, used by $81 \%$ of primary schools and $78 \%$ of secondary schools, and SCRIPT with $10 \%$ and $8 \%$ respectively. This left a very small market share for the other products which were in the main in-house LEA systems though some of these may be purchased, indeed both SIMS and SCRIPT started as in-house LEA systems. It should be noted that very few LEA's adopted a mixed economy i.e. using different systems for primary and secondary. This is very healthy situation for SIMS but I am not so sure it is for ITEM in the UK. It may be that the figures given here are not a true representation as the responses are made by LEAs and therefore they may be unaware of systems purchased by schools, but the majority of schools are still LEA maintained and standardisation of reporting procedures necessitates to a very high degree the standardisation of software across each LEA. LEAs were asked to supply details of proprietary systems that they had considered. Most had considered the two market leaders, but significant numbers had also considered other packages and rejected them for a variety of reasons both commercial and operational. A surprisingly small number had considered the Scottish market leader SCAMP. It would possibly be unfair to report on the perceived strengths and weaknesses of individual proprietary systems here as most systems have undergone further development since the data was gathered. However, general points that were considered important include:

- single entry integrated software is a must;

- user friendly;

- offer facilities required by DES. (e.g. see [8])

- size of user base of the proprietary system. Concerns here were two fold: if the system had a small user base the supplier might not be financially secure, if the package had a large user base how well could this be supported;

- systems suitable for secondary schools were not necessarily suitable for primary schools;

- school based PC systems should be capable of being linked to LEA mainframe to facilitate two-way transfer of data;

- flexible report writer;

\subsection{Hardware}

The picture regarding the type of hardware used by schools obviously must reflect the choice of software. The LAMSAC survey found both the average primary and secondary school with live systems were using single-user IBM compatible computers running under MS-DOS. However, the follow-up survey found that whilst the situation had not changed greatly regarding primary schools, over $70 \%$ of middle and secondary schools were using Local Area Networks with significant numbers being connected to Wide Area Networks. Other significant differences between the two surveys with respect to hardware were the unsurprising shift from daisywheel printers to laser printers, dot matrix/ink jet printers were still widely used, possibly due to their price and/or ability to print on wider paper than laser printers. Large numbers of schools both primary and secondary were now equipped with modems, and a significant trend towards the introduction of document readers was apparent.

\subsection{Consultation, Training and Support}

Three questions were asked concerning the above in the follow-up survey that were not asked in the original survey. In response to the question "Were schools consulted prior to the purchase of systems for administrative use?" six LEAs responded "No", all other LEAs involved schools by running pilot schemes or having representatives on working groups, 
although in some cases only secondary schools were involved in pilot schemes and working groups. In most cases representation on working groups was minimal. In only one case did an LEA claim to consult all the schools within its area. This lack of consultation must mean that systems were introduced into schools without the school examining its information needs, and identifying how computerisation might benefit them.

Training of school staff, both academic and support, was provided when systems were first installed and was normally undertaken by the LEAs own staff, however, six LEAs bought in external contractors. The number of staff trained from each school, the amount of training given, and the way in which it was delivered varied considerably. Most LEAs had opted to train three people per secondary school (the headteacher, and/or deputy, and/or the systems manager, and a secretary), and two people per primary school (the headteacher, and the secretary). Training tended to focus on how to operate the hardware and software. The general pattern for training included time spent on word processing, and time spent on the adopted proprietary package. Quite often the headteacher and secretary were trained at the same time. The split between those authorities who gave the training in a block and those who spread it out over a period of time, with many breaking it down into half day sessions, was very nearly equal. Length of training varied considerably with some LEAs reporting as much as 10 days per secretary, others only 3 days. The mean per secondary school was 6 days training for 3 people, and primary schools received on average 4 days for two people.

Once systems were installed most authorities continued to support schools in a number of different ways. Most LEAs reported setting up support teams to carry out some or all of the following functions: initial installation of hardware and software; updating of software on school systems; supply further training; provide telephone hot-line support; hold surgeries; and give field support to schools. Support teams were often divided into trainers, hardware support, and software support. User groups and regular mailings including newsletters were cited as additional methods employed to support schools.

\subsection{Future requirements}

The major concern expressed here related to the ability of systems to cope with the financial side of LMS, which is not surprising as most of the systems were originally developed prior to the ERA. However once again, the producers of the proprietary systems have in general responded and produced/modified modules that meet the demands. Other future requirements specified included: simpler systems for primary schools; improved analysis and reporting facilities; improved data transfer facilities between LEA and schools; registration/attendance module; easier correction of errors; easier transfer of data between modules; and a system that runs under Windows.

\section{CONCLUSIONS AND RESERVATIONS}

Government legislation and initiatives have led LEAs into wide scale implementation of ITEM systems. Under LMS schools needed computerised management systems in order to take on some of the roles formerly covered by LEAs, and schools now have systems running a range of applications including accounting, pupil records and assessment, staff records, word processing and timetabling.

Systems were introduced at a time of great educational change and it may well be that the changes could not have taken place without computers. However: 
- as systems were largely introduced without, what I believe to be, adequate consultation, it may well be that implementation has not been as smooth as it should have been;

- systems were generally installed at school level ignoring the best practice of systems analysis and implementation from commerce and industry;

- senior management in schools do not appear to have received adequate training in how the systems can be best used to construct a picture of their schools performance, and plan for the future by displaying current trends and modelling different scenario;

- the numbers of machines installed under government/LEA funding are possibly inadequate to directly impinge on classroom teachers;

- software needs to be continually developed to meet the needs of schools (including primary schools), LEAs and the DFE - a Windows environment appears to be a necessity when most new word processors use this system;

“...schools now require help with using their MIS in a more proactive and integrated way, which will not only reduce administrative tasks for teaching staff, but will also support future planning, act as a diagnostic tool for school analysis and evaluation and finally help schools promote themselves in the increasingly competitive education market." [9]

\section{REFERENCES}

1. Bird, P. (1986) Microcomputers in School Administration: 2nd Edition, London: Hutchinson.

2. House of Commons (1988) Education Reform Act 1988: Chapter 40, London: HMSO

3. Coopers and Lybrand (1988) Local Management of Schools. A Report for the Department of Education and Science, London: DES.

4. DES, (1988a) Circular No 7/88 Education Reform Act: Management of Schools, London: DES.

5. DES, (1988b) Education Support Grant: A Grant Circular, London: DES.

6. LAMSAC (1989) Computer-based administration systems in Schools-July 1989: A report on the current use of information technology for Schools Administration in the context of the Education Reform Act 1988, London: LAMSAC.

7. DFE, (1993) Statistical Bulletin 6/93: Survey of Information technology in Schools, London: DFE.

8. DES, (1991) Software for National Curriculum Assessment and Reporting: Official letter to: Chief Education Officers and Headteachers of Grant-maintained schools, London: DES

9. National Council for Educational Technology, (1993) Management Information Systems in Schools: a survey of current practice. An NCET Internal Report. 